\title{
Nós e a Doze: algumas inéditas considerações sobre a mais inédita Conferência de Saúde do país
}

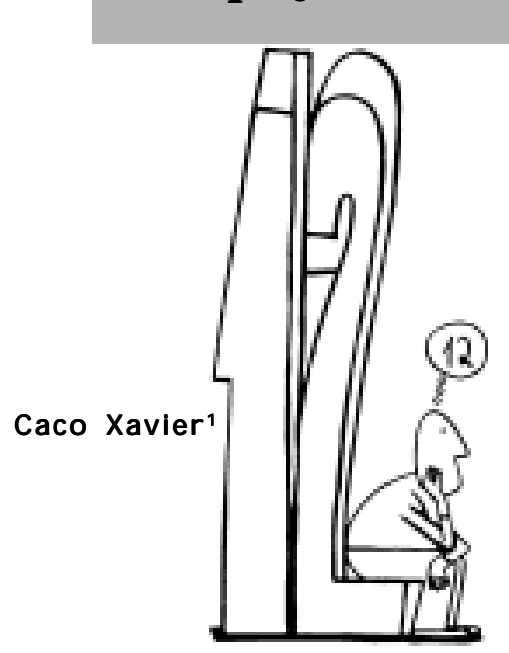

Dia 7 de dezembro, início da noite, e eu correndo feito barata tonta de um lado para o outro da Academia de Tênis, em Brasília, cuidando dos muitos detalhes da área sob a minha responsabilidade na $12^{2}$ Conferência Nacional de Saúde. Eu havia dormido menos de três horas, passado todo o dia anterior, e também todo esse dia, às voltas com os preparativos da etapa nacional da Conferência, e precisava estar atento a tudo. Era a primeira conferência a ser totalmente registrada em vídeo com exceção dos cem grupos de trabalho -, e desse registro dependia ainda a transmissão completa pela internet, em tempo real, ação igualmente inédita.

Corria eu, portanto, entre o salão principal da Conferência e a Sala de Imprensa, tentando integrar as cinco equipes de filmagem, os técnicos responsáveis pela transmissão pela internet e os jornalistas da assessoria de imprensa da Conferência. Além disso, em razão da presença do vice-presidente da República, José Alencar, os procedimentos da segurança e do cerimonial da Presidência exigiam atenção constante. Eu entrava, portanto, atropeladamente no salão onde iniciava-se a

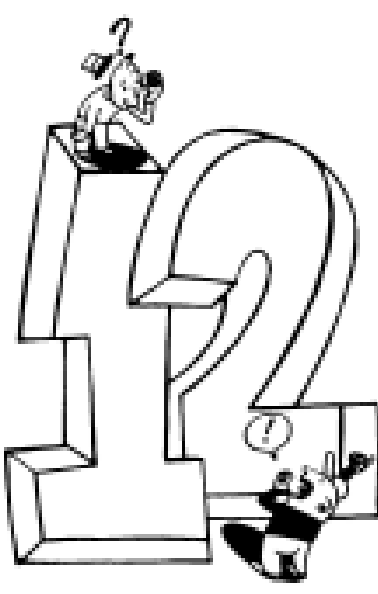
cerimônia de Abertura, com alguma pequena urgência em mente a ser resolvida. Acompanho Conferências Nacionais desde a Nona, mas foi só entrar no chamado Salão Sergio Arouca e a expectativa das quatro mil pessoas que aguardavam o início desta Conferência paralisou-me como um susto. Esqueci o problema que devia resolver e decidi assistir a um pouco da Abertura.

O zumzumzum das muitas vozes, a 'eletricidade' no ar, a certeza de cada um ali presente de que esta seria uma Conferência 'diferente', tudo isso foi confirmado com a chamada dos integrantes da mesa de Abertura. A menção ao nome do Coordenador da Conferência, Eduardo Jorge, fez o povo levantar-se em palmas e gritos num movimento único que lembrava a comemoração de gol do Flamengo em dia de FlaFlu. I mpossível deixar de emocionar-se. Logo a seguir, ouve-se o nome do Ministro da Saúde, Humberto Costa. Para minha surpresa - lembrando-me de como os participantes de uma Conferência costumam recepcionar o ministro da vez-, também ele é saudado com muitas palmas, mais um fato inédito dessa Conferência.

Ali, 'curtindo' a materialidade daquilo que a Comissão Organizadora, o Conselho Nacional de Saúde e muitos colaboradores havíamos construído nos meses anteriores, também eu percebi que havia no ar alguma coisa diferente, algo que movia essa massa de gente. Esperança, confiança, segurança e ainda sentido de responsabilidade. "Arouca está aqui", dizia Sarah Escorel, enquanto no fundo do

\footnotetext{
${ }^{1}$ Jornalista da Fundação Oswaldo Cruz; Assessor especial da Comunicação da 12ª Conferência Nacional de Saúde.
} 
palco lia-se a frase inspirada na vida e nas ações de nosso maior sanitarista, de nosso Estadista da Saúde: “Aqui é permitido sonhar!". Foram tantas reuniões, preparativos, tensões, oficinas, treinamentos! Tanta coisa nova, da metodologia e sistema de Relatoria às ações de comunicação, da organização do Conselho à coor denação executiva apoiada pela recém-nascida Secretaria de Gestão Participativa. Tanta coisa podia dar tão certo, e tanta coisa podia dar tão errado! Era preciso cuidar de tudo, e de tanto! Naquele momento, no entanto, escondido entre milhares de vozes, braços e lágrimas, eu simplesmente respirava fundo e dizia para mim mesmo: "Começou! Começou bem, começou forte!"

A 12a Conferência Nacional de Saúde é um marco, tanto pelo que deu certo quanto pelo que não deu certo. Tudo o que deu certo parece estar definitivamente implantado, e deve ser continuamente aperfeiçoado nas edições que se suceder em. Aquilo que não deu certo, por outro lado, deve necessariamente for çar a reflexão sobre a revisão do modelo sobre o qual são organizadas as Conferências de Saúde. Tudo aquilo que deu certo, deu muito certo, e não se pode imaginar uma próxima Conferência de Saúde sem tais inovações. E tudo aquilo que não deu certo, deu muito errado, a ponto de podermos ousar dizer, com segurança, que esta Conferência foi a última realizada segundo esse modelo. A partir, portanto, de qualquer perspectiva que se olhe, esta 12a Conferência Nacional de Saúde é um marco.

\section{O tom, acorde maior}

Se alguém, hoje, beneficiado pela curta 'distância' que já nos separa de Brasília, me perguntasse qual foi o 'tom' da Conferência, eu diria que foi um acorde maior, composto por três notas da escala: a primeira, a terça e a quinta.

A primeira nota é, sem dúvida alguma, a participação popular. Em animada conversa duas semanas depois da Conferência, no conhecido bar carioca Bracarense, um grupo de amigos do Ministério comentava comigo que a "correlação de forças está mudando" e que alguns sinais já se viam na Conferência. Segundo a análise deles, o que tinha desequilibrado a votação de certos grupos de propostas não tinha sido, como anteriormente, o embate estados $\mathrm{x}$ municípios $\mathrm{x}$ União, ou entre trabalhadores de saúde $\mathrm{x}$ gestores $x$ usuários, mas entre segmentos sociais. Foi lembrada a articulação entre a Pastoral da Criança e lideranças de grupos indígenas, e também o trabalho da Aneps (Articulação Nacional de Movimentos e Práticas de Educação Popular e Saúde), inserindo a educação popular em tudo o que dizia respeito à educação em saúde e à comunicação. Foi lembrada, sobretudo, a participação ativíssima e organizada dos agentes comunitários que, espalhados em praticamente todos os grupos de trabalho, tornaram-se fontes de dor de cabeça para coordenadores de grupo, por sua combatividade ao bater insistentemente na mesma tecla de suas articuladas propostas.

A 'ter ça' que compõe esse acor de maior é a participação, desde o primeiro momento, do Ministério da Saúde, em duas atitudes muito importantes. A primeira foi a reiterada declaração do ministro Humberto Costa de que as deliberações da Conferência serão implementadas, tornando-se a base da política de governo para a área da Saúde. Este é um compromisso inédito, e sua divulgação em massa parece ter sido um dos elementos que proporcionaram a boa acolhida ao Ministro, por parte dos delegados da Conferência, que do mesmo modo certamente exigirão o cumprimento de tal compromisso, tão logo seja divulgado o Relatório Final. A segunda boa atitude do Ministério foi a publicação de suas teses sobre os Dez Eixos Temáticos, o que favoreceu bastante o debate antes e durante a Conferência.

A última nota desse acorde, a 'quinta', ficou evidenciada na Abertura da Conferência, mas não foi nenhuma surpresa para aqueles que já estavam trabalhando e acompanhando a sua organização. Quando o Coordenador Geral Eduardo Jorge abriu mão de sua fala em nome da Relatora Adjunta Sarah Escorel (“Por ser presidente do Cebes, entidade histórica nas lutas da Saúde; por ter sido casada com o sanitarista Sergio Arouca, nosso maior 
homenageado; e por ser mulher!"), a plenária veio abaixo e não se calou enquanto não subiram ao palco uma cadeira para que ela se sentasse à mesa que, adivinha, era composta só de homens. "As estruturas de poder são tão machistas, não?", comentou Sarah, ocupando seu merecido lugar na Abertura.

No dia seguinte, enquanto os releases oficiais da Doze e as matérias de jornal saíam com fotos do Ministro na capa e títulos frios como 'Confer ência começa em tom governista', o singelo Diário da Doze, todo feito por mim e pelo designer Fabiano Bastos literalmente da noite para o dia, saía com a foto de Sarah e a manchete 'Uma Conferência com alma feminina'. É óbvio que recebi alguns delicados 'puxões de orelha' por ter sido tão pouco político, ignorando a presença do Ministro e do Vice-Presidente na Abertura da Doze, mas eu sabia do que estava falando, e não me referia apenas às cerca de três horas da cerimônia do dia anterior.

Conferência com alma feminina, sim, e a frase não era minha e nem tinha sido dita pela primeira vez, já que dias antes a Coordenadora Adjunta Fátima Souza, chefe de gabinete do secretário de Atenção à Saúde Jorge Solla, a havia utilizado para ilustrar as iniciativas que estavam se formando para que o ambiente da Doze primasse pela cordialidade, pelo companheirismo e pelo diálogo. Na verdade, 'masculinos' nessa Comissão Executiva éramos eu, Eduardo Jorge, Paulo Gadelha e Artur Custódio. A 'mão' que guiou quase todos os processos de construção dessa etapa nacional era mesmo feminina: Fátima Souza (Coordenação Adjunta), Márgara Cunha (Secretaria de Comunicação), Sarah Escorel e Ana Costa (Relatoria Adjunta), Eliane Cruz (Secretaria Geral) Marylene Rocha (Infra-estrutura). Isso sem falar na três Meninas Superpoderosas, Florzinha, Docinho e Lindinha (Ana Lúcia Amstalden, Denise Alves e Mariana Sá), que tinham como missão salvar o 'mundo' da Conferência todo dia antes do jantar. Foi uma Conferência com alma feminina, sem dúvida alguma.

\section{0 que deu certo}

Não é necessário que me estenda. O que deu certo nesta Conferência já foi bem explicitado pelo próprio Eduardo Jorge em sua participação no programa Canal Saúde e pode ser descrito em três dimensões. A primeira diz respeito à compreensão da Conferência como um longo processo que se inicia nos municípios e tem o ápice na etapa nacional. Mas não foi uma compreensão meramente teórica. Ela se deu na prática, graças principalmente à metodologia de trabal ho e à construção ascendente de relatórios. A recomendação, portanto, era de que todas as conferências municipais deveriam pautar-se sobre os Dez Eixos, e discuti-los. Assim, cada Conferência municipal apresentava seu relatório à Estadual, que produzia síntese e, por sua vez, gerava um relatório estadual. O Consolidado de 26 relatórios estaduais foi o documento apresentado à plenária da nacional.

A metodologia, definitivamente, deu certo. Ainda há o que aperfeiçoar e lapidar, mas já é possível perceber que dessa forma é possível compor um Relatório Final realmente sintético e propositivo, centrado em ações, e que expresse de fato a vontade da sociedade. Destaq ue-se, também, o trabalho eficiente e criativo do DataSus, que criou, a pedido da Relatoria Geral, um sistema informático para operacionalizar confortavelmente o trabalho dos relatores, ao mesmo tempo em que torna possível o acompanhamento das propostas oriundas dos municípios e estados.

Nem tudo foram flores, no entanto. Lembro-me que, numa reunião de Câmara Técnica

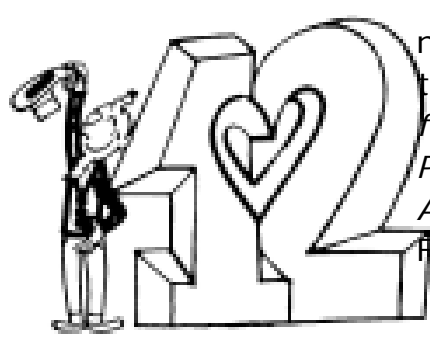

na Fiocruz, o Relator Geral Paulo Gadel ha explicou minuciosamente seu plano de rabalho. Eu, impertinente, fiz logo a primeira pergunta: “A metodologia parece fantástica, e todos estamos torcendo pra que funcione. Mas, cá entre nós, você tem um Plano B, pro caso desse complexo e sofisticado sistema falhar?". "Não. Por isso o Plano A tem que funcionar", respondeu com segurança o Relator, também vice-presidente da filocruz. Apesar do otimismo da resposta, a pulga não saiu de trás da orelha, e cada vez 
que eu ouvia mais detalhes do planejamento, pensava comigo mesmo no mesmo tom de Hardy, a hiena do desenho animado: "I sso não vai dar certo". Mas deu. O Plano A deu totalmente certo, e não foi preciso nenhum Plano B. Pelo menos até a véspera da Plenária da etapa Nacional.

O papel da Informática foi além da construção de um sistema de Relatoria. A inscrição dos delegados e o envio dos relatórios estaduais, por exemplo, foram realizados pela internet, e um eficaz sistema possibilitava que qualquer pessoa conectada à web, em qualquer lugar do país, pudesse conhecer, duas semanas antes da Conferência, a relação completa dos delegados, seus estados e os segmentos que representavam, e também os relatórios estaduais, na íntegra. Não se pode conceber, daqui por diante, uma Conferência que não se utilize de todas as tecnologias de informação e comunicação disponíveis, a serviço da transparência e da construção democrática.

A segunda grande dimensão da Conferência citada por Eduardo Jorge foi a própria área de Comunicação. Um site-r eferência para todas as informações a respeito da Doze, edições do Jornal da Doze, alegre, com jeito popular, a criação do personagem 'Arouquinha', que possibilitou grande simpatia e empatia à Conferência, enfim, foram muitas ações integradas. Mas o diferencial deu-se a partir de duas ações essenciais e inéditas: o registro integral da Conferência, em vídeo - e sua preservação pela Coordenadoria Geral de Documentação e Informação, do Ministério da Saúde -, e a transmissão ao vivo, pela internet, de quase todos os trabal hos, possibilitada pelo DataSus e por uma parceria, também inédita, com a conceituada Rede Nacional de Ensino e Pesquisa (RNP), ligada aos Ministérios da Educação e da Ciência e Tecnologia. Graças a essas ações, essa foi a Conferência mais documentada e mais transparente da história. A terceira dimensão do que 'deu certo' foi a já citada participação social.

\section{O que não deu certo}

É uma questão matemática. Como votar oitocentas propostas e quatro mil destaques em dois dias? Numa jornada de, na melhor das hipóteses, 12 horas por dia, mais de três propostas/ destaques por minuto teriam que ser votados, em dois dias de sessão ininterrupta, para que se conseguisse aprovar o Relatório ainda em Brasília. Missão impossível.

Chegando-se à etapa nacional, o Plano A era ter o Relatório completo às nove horas da manhã do primeiro dia de Plenária, para ser lido inteiramente até às 12 horas. Os delegados, então, apenas se pronunciariam identificando a necessidade de destaques a cada proposta lida, sem ainda externar o conteúdo deles, o que seria encaminhado às mesas criadas para recebê-los. Para que isso fosse possível, os relatores de síntese teriam, então, cerca de 12 horas para sistematizar e incluir a totalidade das contribuições oriundas dos cem grupos de trabalho.

Depois disso, deveria haver uma estrutura eficientíssima de gráficas e copiadoras prontas a imprimir quatro mil exemplares de um pré-Relatório com cerca de cento e vinte páginas, ou seja, quatrocentos e oitenta mil páginas rodadas das duas da manhã (horário estimado em que o relatório estaria pronto) às nove. Outra questão matemática, outra missão impossível. Como destinar apenas uma noite/madrugada para a síntese e impressão de vinte relatórios por eixo?

O resultado é que, apesar do bravíssimo e competente trabalho da relatoria de síntese e dos cerca de duzentos relatores de apoio - que muito contribuíram para que os relatórios dos grupos chegassem 'limpos' à Relatoria de Síntese - e do programa informático que facilitou muito a redação e sistematização dos relatórios -, às nove horas da manhã do primeiro dia de Plenária somente um dos Dez Eixos estava impresso para leitura, e estimava-se que o Relatório só estaria completo no final do dia. $O$ primeiro dia passou-se, assim, totalmente dedicado à leitura conta-gotas do relatório.

À noite, o Consel ho Nacional de Saúde reuniu-se com a Comissão Executiva da

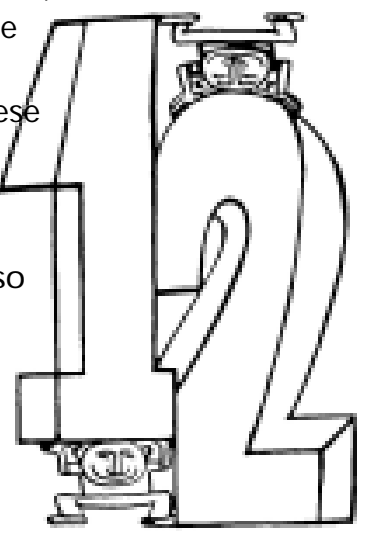


Conferência e com a Relatoria para rever o procedimento e a coordenação dos trabalhos. O quadro era sombrio, já que, no dia seguinte - o último dia da Conferência deveriam ser votados todas as oitocentas propostas e os mais de quatro mil destaques apresentados no dia anterior. Acrescente-se a esse caldo de dificuldades o fato de a cerimônia de encerramento da Conferência estar marcada para as 19 horas, com a presença do Presidente da República, Luiz Inácio Lula da Silva. Isso significava que, não importando a mínima em que estágio estivesse, a Plenária teria que forçosamente interromper os trabalhos às 17 horas, para a tradicional 'varredura' da equipe de segurança da Presidência.

A decisão foi reunir mais uma vez os relatores de síntese para extrair de cada eixo algumas propostas polêmicas ou contraditórias, no máximo de cinco por eixo, selecionadas pelo Conselho Nacional de Saúde. Essas iriam à Plenária para votação. 0 Coordenador da Conferência, Eduardo Jorge, do alto dos seus vinte anos de Parlamento, dizia que o ideal seria encaminhar apenas 25 propostas para votação. Enviaram cinqüenta. $O$ encaminhamento, assim, foi o seguinte: as propostas que não foram alvo de nenhum destaque estavam previamente aprovadas; as cerca de cinqüenta propostas enviadas à Plenária seriam votadas e aprovadas, segundo os critérios de quorum e tempo de apresentação e defesa já previstos; finalmente, as demais propostas, com os destaques expressos em emendas aditivas ou substitutivas seriam encaminhadas aos delegados por correio e por e-mail, que lançariam seus votos em uma planilha de votação e a devolveriam à Relatoria, que então se encarregaria de somar os votos e realizar a redação final do Relatório. Ou seja: somente em - na melhor das hipóteses fim de abril teremos o Relatório Final da 12a Conferência Nacional de Saúde. O atraso não é nenhum bicho de sete cabeças, e já aconteceu - várias vezes - antes. O importante é que o Relatório seja representativo, isto é, que todas as propostas e emendas tenham sido objeto de votação, segundo o quórum estipulado no Regimento.

Este parece ser um consenso: é hora de se propor uma reflexão exaustiva acerca do modelo que utilizamos desde 1986 para organizar Conferências de Saúde. É hora de se rever o papel e a metodologia do trabalho de grupos, mesas temáticas, plenárias. Esta Doze, por seu caráter 'total' e por sua metodologia ascendente de elaboração de propostas, fez desembocar na Plenária Final um volume muito maior de propostas do que o que era esperado. Além disso, as etapas (municipal, estadual, grupos da nacional, plenária) girando sempre em torno dos mesmos eixos possibilitou que propostas que 'caíam' numa etapa fossem sistematicamente re-integradas ao debate nas outras, o que ocasionou um grande desperdício de energias.

As tecnologias de comunicação, algumas inauguradas - ou potencializadas - na Doze, permitem imaginar uma verdadeira conferência on-line em que, sem a pressa e a antecipação desta, possa ter suas discussões estabelecidas ao longo de vários meses entre delegados já credenciados de vários estados. Alguns dizem que o momento do encontro nacional deve ser totalmente dedicado à votação de um documento já estudado e discutido. Outros dizem que, ao contrário, esse deve ser um momento de plena discussão, aberta, participativa. Todos concordam, porém, que esse modelo palestras / grupos de trabalho / plenária está esgotado, é ineficaz e precisa ser revisto.

Com isso concorda também Eduardo Jorge, Coordenador dessa Conferência. Suas palavras, na Carta de Agradecimento que enviou aos participantes, apontam uma importante direção: "Este modelo de Conferência precisa ser superado. A próxima Conferência precisa ser muito mais Acre, Piauí, Paraíba e Santa Catarina do que Brasília".

\section{Encerramento: o Lula vem? O Lula foi.}

A presença de Lula no Encerramento dividiu opiniões. A maioria dos participantes gostou de ver o apoio do Presidente da República à Conferência, apesar do tom, 
digamos, pouco assertivo de suas palavras, já que os delegados esperavam a confirmação do compromisso expresso pelo ministro Humberto Costa. Outros reclamavam das 'conseqüências' da vinda do Lula, já que esta exigiu grande aparato de segurança e a inflexibilidade própria das estruturas de poder. No caso da Conferência, ela praticamente teve que ser paralisada na hora mais 'quente' das discussões em plenário, em virtude dos rígidos horários e procedimentos requisitados pelo Cerimonial da Presidência.

Todos já sabiam: haveria uma cerimônia de Encerramento, mas nada de 'encerramento', porque os delegados voltariam à plenária para votar até o fim as propostas encaminhadas. Nesse Encerramento simbólico, portanto, imagens variadas da Conferência, incluídas no clip do Hino Nacional, belissimamente editado pelo Canal Saúde, emocionaram cada um e fizeram renovar as for ças dos delegados. Às seis da manhã, esgotados e felizes, a etapa nacional da 12a Conferência Nacional de Saúde oficialmente terminou. Quer dizer, quase. Documentos contendo todas as emendas e destaques sugeridos pelos delegados estão sendo encaminhados nesse momento a suas casas - ou a seus computadores - para serem avaliados e aprovados. Só depois que os relatores sintetizarem o resultado final dessa votação a distância - mais um ineditismo dessa já tão inédita Conferência - é que poderemos dizer: "acabou".

Para encerrar esse artigo, volto à cerimônia de Abertura, quando um grupo de teatro encenou uma rápida apresentação em que, brincando com a noção bíblica de 'primeiro, segundo, terceiro dia...', chega ao sétimo dia, o do descanso, e se pergunta: "Mas e no Oitavo Dia, o que aconteceu?". "No Oitavo Dia a conteceu a Oitava!", diz o ator. Arlindo Fábio, superintendente do Canal Saúde, chefe de gabinete da presidência da Fiocruz e Relator Geral da Oitava Conferência de Saúde não se conteve: "Espera aí! Quer dizer que quem fez a Oitava foi... Deus??? Eu jurava que tínhamos sido nós!".

Ninguém duvida disso, Arlindo! E ninguém duvida também que essa Doze foi realizada por esse mesmo 'nós', sempre renovado e renovador. O grande desafio, a partir de agora, está expresso na segunda parte da frase que criei para ilustrar uma Carta de Boas Vindas da Conferência e que acabou estampada no fundo do palco. "Aqui é permitido sonhar", já sabemos e comprovamos, no SUS é permitido sonhar, e é por isso que estamos aqui. Agora queremos saber se, no que diz respeito à Doze, "aqui é permitido realizar o sonho sonhado". De quem depende? Mais uma vez, de 'nós'.

XAVIER, C.We and the "Twelfth": novel thoughts on the most novel Health Conference in the country, Interface - Comunic., Saúde, Educ., v.8, n.14, p.191-4, set.2003-fev.2004.

It concerns a critical evaluation of the facts and significant moments of the 12th National Health Conference, presented by one of the persons responsible for organizing the event. KEY WORDS: Health; public policies.

Trata-se de uma avaliação crítica de fatos e momentos significativos que marcaram a $12^{a}$ Conferência Nacional de Saúde, apresentada por um dos responsáveis pela organização do evento.

PALAVRAS-CHAVE: Saúde; políticas públicas.

Se trata de una evaluación crítica de hechos y momentos significativos que marcaron la $12^{\mathrm{a}}$ Conferencia Nacional de Salud, presentada por uno de los responsables por la organización del evento. PALABRAS CLAVE: Salud; politicas publicas.

Recebido para publicação em 15/01/04. Aprovado para publicação em 04/02/04.

196 Inteface- Comunic., Saúde, Educ., v.8, n.14, p.191-6, set.2003-fev.2004

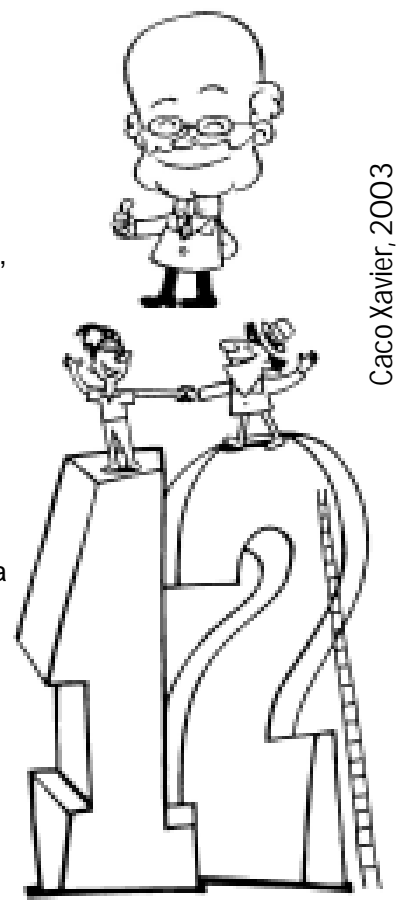

